\title{
Circulation Dynamics to Improve Commercial Activity in a Mega Mall
}

\section{Joon-Bum Kwun and Duk-Su Kim}

Assistant Professor, Department of Architecture, Sejong University, Seoul, Korea

Assistant Professor, Department of Architecture, Hanbat National University, Daejeon, Korea

\begin{abstract}
The 'one-day-shopping' concept that we experience today in a modern mega mall changed the propensity to consume compared to the past. The idea of a mega mall originated in the U.S. and the first suburban shopping malls as we know them today were built in the 1950s. The convenience of these malls had a great impact not only on consumers but also on the retail industry in general and the new mega mall idea has since spread around the world, with the largest ones located in China and Southeast Asia. Meanwhile, Korea had the fastest-growing economy during the last three decades and with that boom the compositional structure of domestic retail facilities became extremely diverse. Today, there are 36 new mega mall development plans to be completed before 2016, which represent a rapid and dynamic change in consumerism lifestyle in Korea. In this regard, this study will re-evaluate the first mega mall in Korea, the COEX Mall, and identify initial errors regarding its circulation plan and provide an ideal design strategy for future commercial mega malls based on literature review and comparison analysis.
\end{abstract}

Keywords: Mega Mall, Anchor Tenant, General Tenant, Tenant Mix

\section{INTRODUCTION}

(1) Research Background

The overall process to develop a mega mall is accomplished through extremely complex procedures from programming/ schematic plans to management issues and, above all, the most critical consideration in designing a successful mega mall heavily relies upon an elaborated tenant mix plan. ${ }^{1}$ Nevertheless, in Korea, this most important tenant mix plan has a tendency to be decided not by a retail expert but by a developer, who is also the land owner in most cases, and by the major merchandisers, whose interests are mainly focused on their own company's profit instead of the overall active facility consumptions. An absurd and irrational tenant mix plan can impact the whole circulation dynamics and may have a direct negative impact on sales turnover and the coefficient of utilization and its 'superiority and suitability' between tenants can

Corresponding Author : Duk-Su Kim, Associate Professor

Department of Architecture, Hanbat National University, Daejeon, Korea

Tel : +82-42-821-1744 e-mail : dsk4pm@gmail.com

This is an Open Access article distributed under the terms of the Creative Commons Attribution Non-Commercial License (http://creativecommons. org/licenses/by-nc/3.0/) which permits unrestricted non-commercial use, distribution, and reproduction in any medium, provided the original work is properly cited.

\footnotetext{
${ }^{1}$ Bae, B.K (2010) The New Era of U.E.C(Urban Entertainment Center), Fashionbiz, January, 181-187
}

appear 3 to 6 months later. ${ }^{2}$ Thus, if the first initial plan fails, then it can take at least three months to even several years to fix the initial flaws and the most serious problems due to business shut outs, leading to the no utilization of commercial space, which will eventually reduce overall profit. ${ }^{3}$

Meanwhile, the first multipurpose facility in Korea is the Korea World Trade Center: COEX (COnvention \& EXhibition) that was built in 1979. It was totally a new architectural concept at the time, and later in 2000, an underground mega mall was built. Due to its enormous success, its design strategy and spatial composition became a prototype to many similar mega malls in Korea. Furthermore, according to the future plans, COEX Mall connected with subway line 2, which is the Samsung Station, will be connected with the new subway line 9, ASEM Station, and also has a partial remodeling plan scheduled to be completed by 2014. On account of this, the intention of this study is to identify any initial design

\footnotetext{
2 Anita, K., et. al. (2008) Retail Development, 4th Edition, ULI Development handbook series. Washington D.C., ULI-the Urban Land Institute

3 The mega mall 'Garden Five', which opened in 2009 in Korea, failed in commercial lots sale and lost enormous amount of money as in 2013 and it is still struggling under deficit operation. The Shops at the Garden Five was supposed to create hundreds of new jobs but among 8360 commercial lots, 1300 lots are still on sale and 4,000 lots are currently out of business. In fact, it was never fully occupied, and it seems that this facility ended up in trouble anyway because of poor site selection and misguided leasing efforts. Currently, this unfortunate example is undergoing a major, yet questionable renewal plan.
} 
errors regarding the circulation plan of the first mega mall in Korea (COEX), and propose an ideal compositional strategy based on literature review and several case studies.

\section{(2) Limitation}

Generally speaking, the term 'tenant mix' traditionally refers to the specific combination of businesses types based on brands, retail items and services in a shopping mall. The meaning of tenant mix in this study, however, will be limited to mutual interaction and spatial composition that can impact the overall circulation dynamics. Also, despite the different physical condition between an underground mega mall and an ground mega mall, this study will assume that the internal circulation dynamics will have a similar pattern in terms of internal consumption and compositional efficiency. Furthermore, due to the different business scale and commercial infrastructure between Korea and the U.S., it may not be appropriate to make a direct comparison analysis but the accumulated knowledge on compositional efficiency through times and its circulation dynamics were worth to investigate.

(3) Significance and Methodology

The first initial tenant mix plan of the COEX Mall has most of its main anchor tenants skewed toward Young-Dong Boulevard, which is the main street of its site and is connected with subway line 2, Samsung Station (lower left corner in figure 1). Also, almost every important open space including the main gate is placed toward Young-Dong Boulevard. Therefore, it obviously creates significantly higher amount of floating population traffic between individual general tenants located at major connecting arcades at the front compared to those who are located towards the back side of Young-Dong Boulevard. Moreover, the future ASEM Station of subway line 9 is planned to be located at the very opposite end of the existing station, which is also skewed toward the Young-Dong Boulevard which could cause even more unequal floating population traffic flow. In other words, before the re-modeling plan, most visitors at least had to turn around and had to go back to the main gate to exit this facility but the new plan with a new subway station may cause a one-way visitor flow that will make stronger deviation regarding floating population traffic flow amongst individual general tenants that are located at the front versus those at the backside of Young-Dong Boulevard.

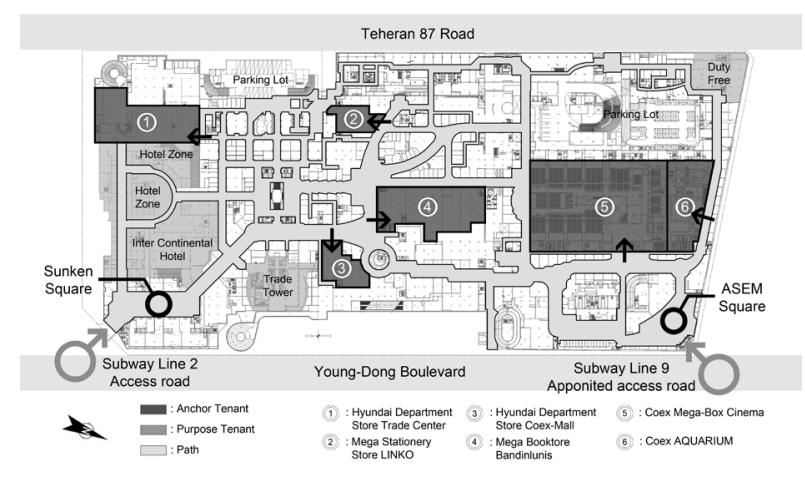

Figure 1. The COEX Mall floor plan

In this regard, this study will re-evaluate the existing circulation plan of the COEX Mall based on past research findings and make a comparison analysis between successful worldwide known mega malls to prevent irregular commercial activity. Eventually, this research will identify a profit oriented compositional strategy of a commercialized mega mall for future reference.

\section{LITERATURE REVIEW}

\section{(1) Tenant Mix Plan}

Studies on existing mega commercial facilities are usually focused on typological categorization, retail spatial analysis and visitor' satisfaction. On the other hand, the most important criteria and factor in judging a successful mega mall heavily relies on its total gross. As long as the total gross is low, then it would be practically difficult to maintain its original function as a multipurpose commercial facility. Besides many external variables that can influence total gross such as environmental factors, commercial supremacy, land cost and construction cost, the tenant mix plan that can manipulate circulation dynamics would be one of the important internal variables to premise a successful mega mall. However, developers, who have the most influence in facility operations, are usually interested in which big name power tenant can pay the highest rental value instead of mutual interactions between the anchor and individual tenants that can promote vigorous commercial activity. ${ }^{4}$ According to Lee (2004), five functional categories that can compose a well balanced tenant mix plan are the anchor tenant, sub-key tenant, magnet tenant, individual general tenant and specialized tenant. ${ }^{5}$ Similarly, Beyard (2001) explained the tenant mix plan with three typological categories; retail tenant, food/beverage tenant and entertainment tenant. $^{6}$

Table 1. Tenant Classification

\begin{tabular}{|c|c|c|}
\hline \multirow{5}{*}{ 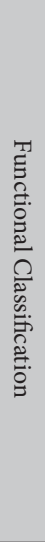 } & Anchor & $\begin{array}{l}\text { - Privilege for the pre-occupancy prior } \\
\text { general tenants. } \\
\text { - Distinctive contribution to the image } \\
\text { of a mall. } \\
\text { - Strongest impact on commercial } \\
\text { feasibility. }\end{array}$ \\
\hline & Sub-key & $\begin{array}{l}\text { - Positive impact in building attraction } \\
\text { - Large specialty store, D.I.Y. and etc. }\end{array}$ \\
\hline & Magnet & $\begin{array}{l}\text { - Attracts consumers with price and etc. } \\
\text { - Tenants with secondary magnitude than } \\
\text { anchor tenants. }\end{array}$ \\
\hline & General & $\begin{array}{l}\text { - Individual general tenants. } \\
\text { - Complementary measures to anchor } \\
\text { tenants }\end{array}$ \\
\hline & Special & $\begin{array}{c}\text { - Spaces for special purpose like rental } \\
\text { office, nursing room, information center } \\
\text { and etc. }\end{array}$ \\
\hline \multirow{3}{*}{ 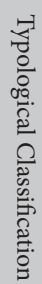 } & Entertainment & $\begin{array}{l}\text { Movie complex, casino, game center, } \\
\text { aquarium, concert hall and etc. }\end{array}$ \\
\hline & Food & $\begin{array}{l}\text { Food court, fast food brands, coffee shop, } \\
\text { restaurant and etc. }\end{array}$ \\
\hline & Sale(Service) & $\begin{array}{l}\text { Retails like individual tenants, brand } \\
\text { stores, outlets or service facilities like } \\
\text { bank, clinic, customer service and etc. }\end{array}$ \\
\hline
\end{tabular}

${ }^{4}$ Sullivan, M. (1988) Leasing Trends: Which Tenant Brings in the Most Rent?, Chain Store Age Executive, May, 92

${ }^{5}$ Lee, D.H., et. al. (2004) Shopping Center Development \& Management, Seoul, Diamond Consulting

${ }^{6}$ Beyard, M.D., et. al. (2001) Developing Retail Entertainment Destinations, 2nd Edition, Washington D.C.: ULI-the Urban Land Institute 
Table 2. Functional Characteristics of a Multipurpose Facility

\begin{tabular}{l|l|l|l}
\hline \multirow{4}{*}{$\begin{array}{l}\text { Compo- } \\
\text { sition }\end{array}$} & Horizontal & $\begin{array}{l}\text { Single story composition } \\
\text { without vertical connections. }\end{array}$ \\
\cline { 3 - 4 } & & Vertical & $\begin{array}{l}\text { Multi story composition with } \\
\text { relatively smaller floor area. }\end{array}$ \\
\cline { 3 - 4 } $\begin{array}{l}\text { Multi- } \\
\text { Purpose } \\
\text { Facility }\end{array}$ & \multirow{4}{*}{ Layout } & $\begin{array}{l}\text { Ortho- } \\
\text { gonal }\end{array}$ & Lixed composition of above. \\
\hline & Liberal & Incoherent free visitor flow. \\
\cline { 3 - 4 } & Racetrack & O shape visitor flow. \\
\cline { 3 - 4 } & One-way & $\begin{array}{l}\text { Single arcade with two anchor } \\
\text { tenants on each side. }\end{array}$ \\
\cline { 3 - 4 } & \multirow{2}{*}{ Circulation } & $\begin{array}{l}\text { Indoor version of traditional } \\
\text { market place with connecting } \\
\text { arcades. }\end{array}$ \\
\cline { 3 - 4 } & Mall & $\begin{array}{l}\text { Usually placed at an } \\
\text { intersectional area of } \\
\text { circulations. }\end{array}$ \\
\hline
\end{tabular}

In addition to above conceptual categories, a significant number of studies are focused on spatial analysis and claims that diverse retail dynamics accelerate overall consumption, that makes convenient one-day shopping possible. In terms of convenient shopping, Yoo (2011) claimed that convenience and mutual synergy effect based on many different retail varieties extend visitors length of stay inside a mega mall, so at the very least retail, Food / beverage and entertainment should be accommodated simultaneously. ${ }^{7}$

A variety of many individual retail tenants will also provide comparison shopping and one-stop shopping possible which will extend buyers' length of stay and attract more visitors. ${ }^{8}$ Wakerfield (1988) also claimed that various sales items provided by numerous individual general tenants will have a direct impact on visitors' delectability, which will have a positive effect on their expenditure, length of stay and future return visit. ${ }^{9}$ Contrary to this, uniformity between retail tenants selling mediocre goods may have a negative effec $^{10}$ and as Fujita (1998) argues; different characteristics and competiveness among general individual tenants will also satisfy visitors' shopping needs and desires ${ }^{11}$ Besides sales items among tenants, mutual interactions between anchor tenants and individual general tenants based on distance and moving traffic time should also be carefully considered in designing a tenant mix plan.

\footnotetext{
7 Yoo, I.K., Choi, S.H. (2011) A Study on the Entertainment Contents Elements of Urban Entertainment Centers for Attraction of consumers, Journal of the Architectural Institute of Korea, 27(1), 39-46

${ }^{8}$ Berman, B., Evans, J.R. (1995) Retail Management: A Strategic Approach, 6th Edition, Englewood Cliffs, N.J Prentice Hall

${ }^{9}$ Wakefield, K.L., Baker, J. (1998) Excitement at the mall: Determinants and Effects on Shopping Response, Journal of Retailing 74(4), 515-539

${ }^{10}$ Ha, S.J., Park, E.K., Ha, M.K., (2009) A Study on the Store Attributes of Urban Entertainment Center, Journal of the Architectural Institute of Korea, 25(9), 151-158

${ }^{11}$ Fujita, M. (1989) Urban economic theory: Land Use and City Size, New York, Cambridge University Press
}

Meanwhile, a significant amount of studies are focused not only on the tenant mix plan, but also on the overall spatial composition style of multipurpose retail facilities concentrating on visitors' circulation patterns, which has a direct relation with site and floor planning. As an example, Lee (2012) strongly recommended a so called race-track style plan that can provide continuous linkage between every tenant with maximum exposure to visitors ${ }^{12}$

\section{(2) Anchor-General Tenants and Intermediating Spaces}

Intermediating spaces and connecting corridors between anchor tenants plays a major role in composing a mega mall. Generally, anchor tenants have the strongest impact on commercial feasibility and make a distinctive contribution to the image of the mall due to their brand name power and a relatively huge rental space. For instance, a big name department store is a definitive example of an anchor tenant. This sort of anchor tenant usually has the priority in locating their store in a mega mall. Intermediating spaces, on the other hand, include plazas or event courts were visitors can stay for casual rest and it is usually located on an intersectional pathway. Han (2010) defined an intermediating space in a mega mall as an open space that is usually located in an intersectional circulation traffic point that may make visitors' spatial boundary cognition vague and, therefore, it is necessary to locate a dense number of individual general tenants surrounding an over scaled open space for easy spatial comprehension. ${ }^{13}$ He also argued that well designed intermediating open spaces along with several anchor tenants will be effective as some sort of cognitive landmark to understand an over scaled mega composition. Furthermore, he also argued that equally positioned anchor tenants and intermediating space in distance and travel time is helpful to visitors to understand the overall compositional spatial structure of a mega mall. Similarly, in terms of sales turnovers, Abratt (1985) claimed that a plan with equal distance and travel time between tenants will stimulate more profit and, therefore, it is necessary to avoid any tenant mix plan that can cause an unbalanced circulation pattern. ${ }^{14}$ Finally, it can be argued that locating anchor tenants and key facilities based on visitor's activity or on economic points of view will be an important factor in planning a tenant mix plan to create a synergy effect between retailers that yields higher total sales for individual general tenants than they could achieve on their own.

\section{FRAMEWORK OF THE ANALYSIS}

\section{(1) Site: The Korea World Trade Center, COEX}

The Korea World Trade Center, which is a multipurpose facility known as the COEX, opened in 1979 with hotels, conference and exhibition facilities. Later in 2000, its underground mega mall as we know it today was designed. It is also the most visited mega mall with an average of 140,000 visitors per day in weekdays and approximately 250,000 visitors per day during weekends.

12 Lee, H.S., Oh, J.A. (2012) A Study on the Planning Strategy of Tenant Variety and Placement for Urban Entertainment Center, Journal of the Korean Institute of Interior Design , 21(2), 174-185

13 Han, G.Y., Park, A.R., Park, B.K. (2010) The Mechanism of Space Cognition of Large Mixed-use Complex, Journal of Urban Design, 11(2), 199-214

14 Abratt, R., Fourie, J.L., Pitt, L.F. (1985) Tenant Mix: The Key to a Successful Shopping Centre, Quarterly Review of Marketing, 15, 19-27 
Table 3. Outline of the Korea World Trade Center: COEX

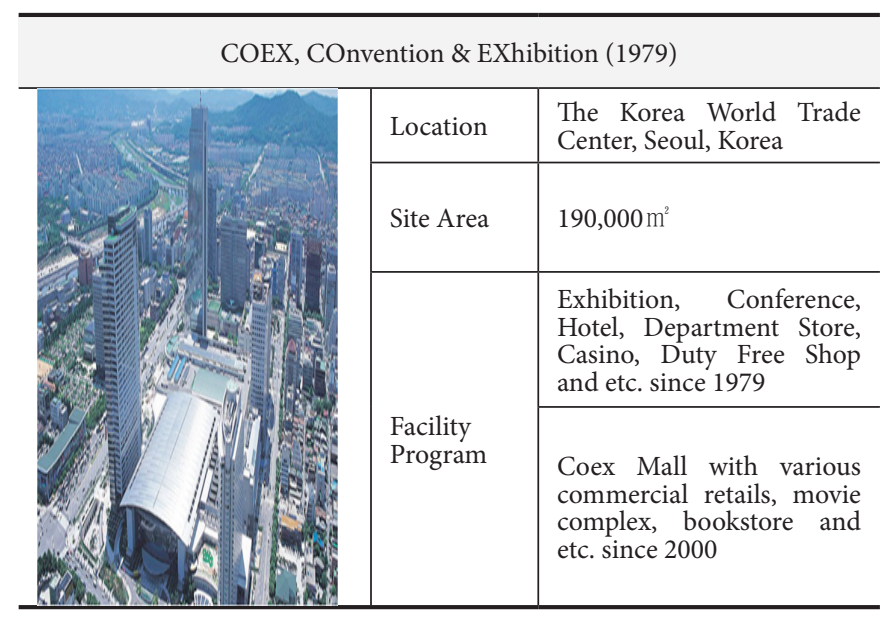

(2) Scope of the Analysis

The basement level of the Korea World Trade Center is composed with the COEX mega mall, Lotte Duty Free Shop, City Airbus Terminal, two Hyundai Department Stores and two Intercontinental Hotels. These facilities are all physically connected to each other, so general visitors may not sense the physical boundaries of these separate facilities. Furthermore, high attraction facilities such as department stores are in fact located right next to the COEX mega mall. Therefore, it will be necessary to analyze the whole B1 level of the Korea World Trade Center except specialized facilities such as Hotels, Airbus Terminal, Casino and the Duty Free Shop. In other words, facilities that have less relationship with general floating population traffic will be excluded for this study.

\section{(3) Defining Anchor Tenants}

This study conducted a comparison analysis between the COEX Mall and five selected mega malls in the U.S. to identify planning strategy that can maximize commercial activity and utilization. The main reason for choosing mega malls in the U.S. is to conduct a comparison analysis is as follows. First of all, the concept of today's mega mall originated in the U.S. and it has the longest history in planning mega malls. Second of all, the number of mega malls in the U.S. overwhelms other countries. Therefore, its accumulated knowledge on compositional efficiency through times would be valuable to investigate. Third, the U.S. has the largest and the most competitive business scale. Its various commercial characteristics and appearances reflect recent Korean domestic business trends and, thus, its transitional guidance can be also a valuable reference to predict future mega mall planning in Korea.

This study assumed department stores as the only type of anchor tenants when analyzing selected mega malls in the U.S. Regarding parking areas, they were excluded for analysis because they had more operational relationship with external variables such as entrance and other outside factors than internal circulation and conveniences. An annexed building was also excluded from this analysis because in most cases, its approach was only possible from a certain floor or area and its existence was not even coherent. In analyzing anchor tenants for the COEX Mall, this study took an identical approach in categorizing and excluding types of facilities but had to consider domestic and realistic conditions and included not only department stores but also large size retailers that are specifically indicated as anchor tenants in the COEX internet homepage. As a consequence, two Hyundai Department Stores, Megabox Movie Theater Complex, Bandi \& Luni's Bookstore, COEX Aquarium and Linko Office Supply Depot were considered as an anchor tenant.

\section{(4) Analytical Methodology}

To evaluate basic interactive forces among anchor and individual tenants, this study measured the number of individual general tenants that are located between anchor tenants. The circulation path between anchor tenants was determined based on the shortest physical distance and/or on main arcades that connect certain anchor tenants, because it is known that general pedestrians have a tendency to choose the shortest or active pathway. ${ }^{15}$ An ideal arcade's circulation between certain anchor tenants also be the shortest distance in accordance with the main pathway but, if this is not the case, then a pathway that has the most individual general tenants was chosen for the analysis. The meaning of individual general tenants in this study indicates shops, stores, restaurants, etc. Facilities that have less direct influence on commercial activities such as restrooms, nursing rooms, escalators and elevators were not included in this analysis.

\section{COMPARISON ANALYSIS AND FINDINGS}

This section will present a comparison analysis between selected shopping centers in the U.S. and the underground mall of the Korean World Trade Center, COEX Mall. Based on the analysis and findings, this study will suggest a profit oriented strategy that can also maximize its facility utilization.

(1) Analysis of Five Selected Mega Malls in the U.S

This study selected five shopping malls in the U.S.; Mall of America, King of Prussian Mall, Houston Galleria, South Coast Plaza and Woodfield Mall, which can all represent a typical strategic plans for commercial facilities. These malls are voted as the most visited malls in the U.S. in 2011 and are located over the entire region of the U.S.15) The analysis of a typical floor plans of five selected malls is shown in Table 4.

The analysis revealed that each arcade that connects two certain anchor tenants contains an average of $38.97 \%$ of the entire individual general tenants. On the other hand, only an average of $8.87 \%$ of the entire individual general tenants were not exposed to any main arcade or pathway that connects anchor tenants. In the case of the arcade that connects 'Saks Fifth Avenue' and 'Bloomingdale's' in Houston Galleria, it contained as many as 90 retail shops among 124 , which showed the highest ratio $(69.76 \%)$ of all the analyzed malls in the U.S.

The five selected U.S. mega malls had usually four to five anchor tenants with simple arcade circulation system and each arcade contained an average of $38.97 \%$ of the entire general individual tenants. This is because all the analyzed mega malls in the U.S. intentionally positioned their anchor tenants at the very end of its circulation to induce impulsive commercial activity and eliminated all the unnecessary sub pathways that can decentralize or diffuse

\footnotetext{
15 Lee, K.H. (1997) A Study on Human Behavioral Patterns in Building Fires and Application of Theirs to the Designing of Escape Routes, Journal of the Architectural Institute of Korea, 13(7), 83-93
} 
Table 4. Analysis of Selected Shopping Malls in the U.S

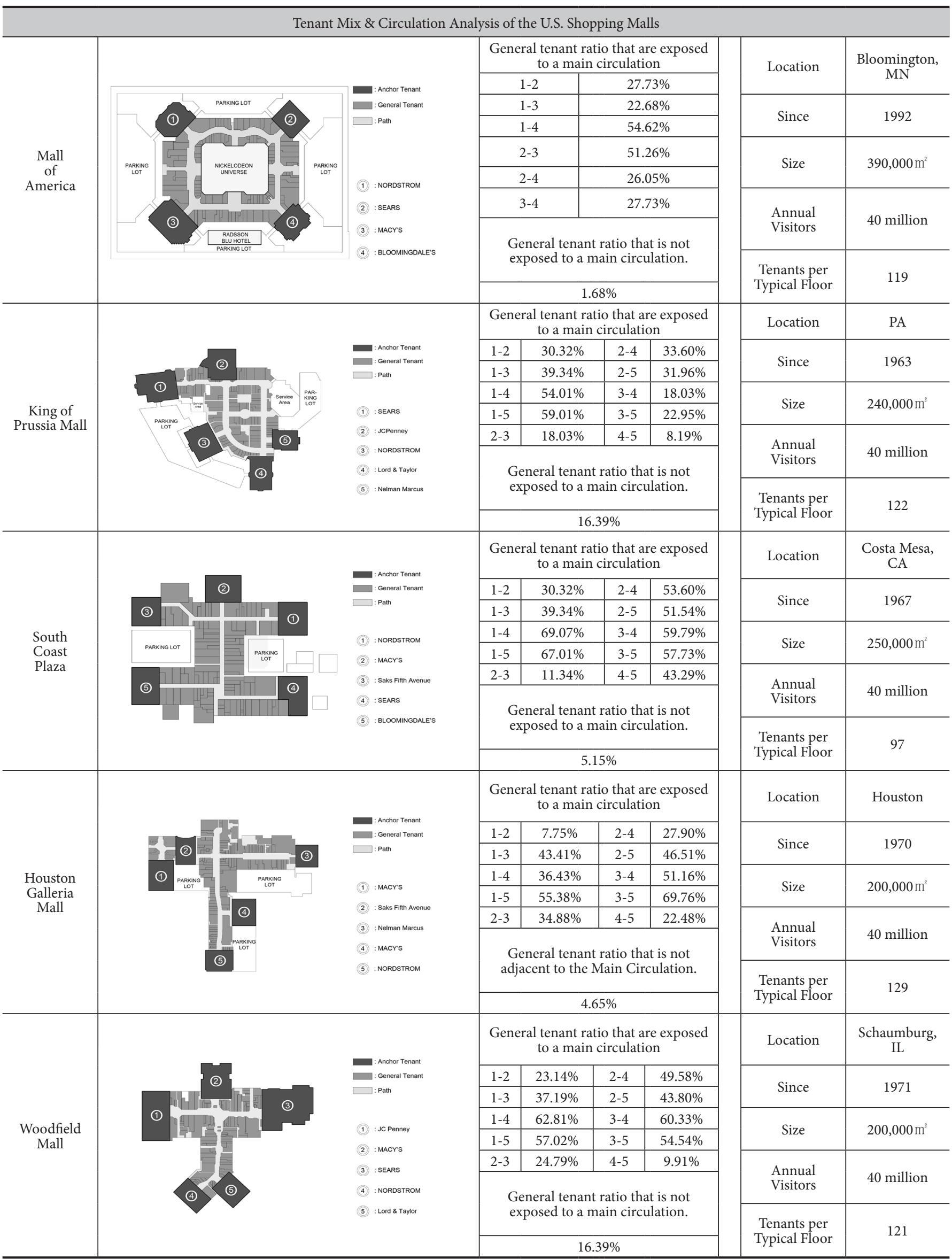


visitor. As a consequence, all of the five selected mega malls in the U.S. had an arcade that also coincides with the physically shortest connection between anchor tenants.

\section{(2) Analysis of the COEX Mall}

The analysis of the COEX Mall was conducted with the same method, as shown in Table 5. Several arcades/pathways that connect two certain anchor tenants contained only an average of $12.63 \%$ of individual general tenants, which is a huge difference with the average of $38.97 \%$ of selected malls in the U.S. The highest ratio in the COEX Mall appeared in an arcade/pathway between Linko, a large office supply depot, and the COEX Aquarium (26.79\%), which was even lower than the average ratio of five selected malls in the U.S. Furthermore, the lowest ratio appeared at the arcade/pathway between the Megabox, a multi movie theater complex, and the COEX Aquarium, which was only $4.50 \%$ due to its short distance between these two facilities.

The most different characteristic between the COEX Mall and the selected malls in the U.S. is that most of the anchor tenants at the COEX Mall are located near the center of its facility. On this account, its main arcades between certain anchor tenants was not necessarily the physically shortest distance and, in some cases, a shorter sub path contained more retail shops than a related main arcade/pathway, which caused an unpractical utilization and operation between main and sub pathways. Furthermore, an average of $47.21 \%$ of all the general individual tenants were not exposed to a main arcade/pathway, which is relatively a high ratio compared to the selected malls in the U.S. with only $8.87 \%$.

\section{IMPLICATION}

The usual planning process in designing a mega mall starts with positioning major anchor tenants prior to individual general tenant. This is a common procedure not only in Korea, but also in the U.S. However, there are different assumptions regarding specific block planning. In the U.S., several famous department stores are considered as major anchor tenants in planning a mega mall as can be seen in the Mall of America. On the other hand, due to the different business scale and commercial infrastructure between Korea and the U.S., it was not appropriate to consider department stores as the only anchor tenant type as in the U.S. Moreover, in the U.S., most of the department stores has the land ownership and to maximize commercial operations, even a gratuitous contract would be offered by a developer. By contrast, in Korea, usually one department store, a large movie theater complex and a large bookstore are considered as anchor tenants that have the privilege for pre-occupancy over prior general tenants. This conventional custom often accepts anchor tenants' requirements actively and preferentially. As a result, anchor tenants in a Korean mega mall have the advantage of locating their business in a more profitable spot, which would be close to the center of a mega mall, and inevitably forms a concentrated anchor tenants' territory at the very center as can be seen in COEX Mall.

Furthermore, most of the mega malls in the U.S. are designed with multiple stories and its arcade and/or open spaces usually have a void in spatial conditions. Therefore, when a shopper walks around an arcade/pathway that connects certain anchor tenants, then individual general tenants, even those on a different floors, might be partially exposed to general shoppers. In other words, if we assume that a general person with average vision can identify objects within a view range of 70 degrees, ) then the differences between the COEX Mall and the selected malls in the U.S. will be even greater because the COEX Mall is a single story underground mall that has no void open areas.

Nevertheless, the COEX Mall is still the most visited mega mall in Korea and is scheduled to be remodeled to provide an opportunity to fix its initial plan to engineer a better shopping environment, thus gaining improved operational performance. In this regard, this study suggests several planning issues based on research findings as follows.

First of all, anchor tenants should be decentralized and should function as the key variable that facilitates shoppers' compulsory circulation to provide better commercial activity along with

Table 5. Analysis of The COEX

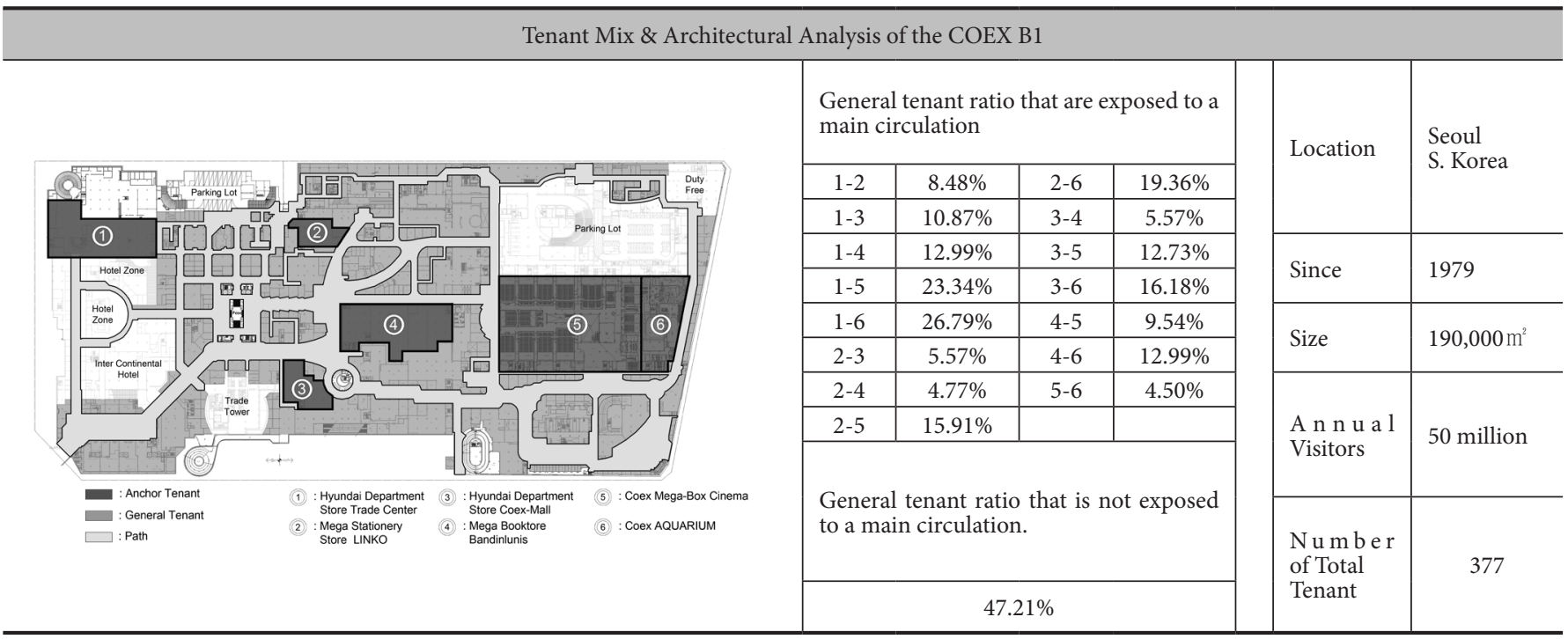


individual general tenants. As this study revealed, only an average of $12.63 \%$ of the individual general tenants were exposed to main arcades/pathway that connects certain anchor tenants, which is relatively low compared to the average of the selected malls in the U.S. (38.97\%). Academic evidence supports this suggestion by arguing that anchor tenants should be placed at the extreme opposite area to extend shoppers visiting time and expose as many individual general tenants as possible to a main arcade/pathway that connects certain anchor tenants. ${ }^{16}$ ) Based on the findings of this study and also on existing research, the future re-modeling plan of the COEX Mall should consider re-positioning Bandi \& Lunis Bookstore, Linko Office Supply Depot and one of the Hyundai Department Stores to induce shoppers' compulsory circulation. These facilities would be practically easier to re-position than the Megabox Movie Complex and the Aquarium, which both have complicated spatial requirements with special equipment.

Second of all, the future re-modeling plan of the COEX Mall should consider eliminating as many sub pathways as possible that causes dispersion of floating population traffic. As this study indicated, the average ratio of individual general tenants that are not exposed to any main arcades/pathways for the selected malls in the U.S. was only $8.87 \%$, which was more than five times smaller than that of the COEX Mall (47.21\%). As Brown (1991) argued, anchor tenants are able to facilitate shoppers' compulsory circulation. In this regard, it would be advantageous to locate as many individual general tenants toward an arcade/pathway that connects certain anchor tenants and reduces blind spots.

Lastly, a specific recommendation is made for the Megabox Movie Theater Complex, which is the largest anchor tenant in the COEX Mall. As seen in the Figure 2, audiences are forced to exit toward one of the main pathways at the opposite area of its main entrance. Nevertheless, it is just an empty pathway with advertising billboards on the wall despite its high potential as an arcade with individual general tenants. Therefore, facilities that are practically impossible to re-position, due to complicated spatial conditions and special equipment, such as the Megabox Movie Theater Complex and the Aquarium, should not neglect their adjacent pathways as seen in Figure 2, but should consider installing individual general tenants to revitalize active commercial operations.

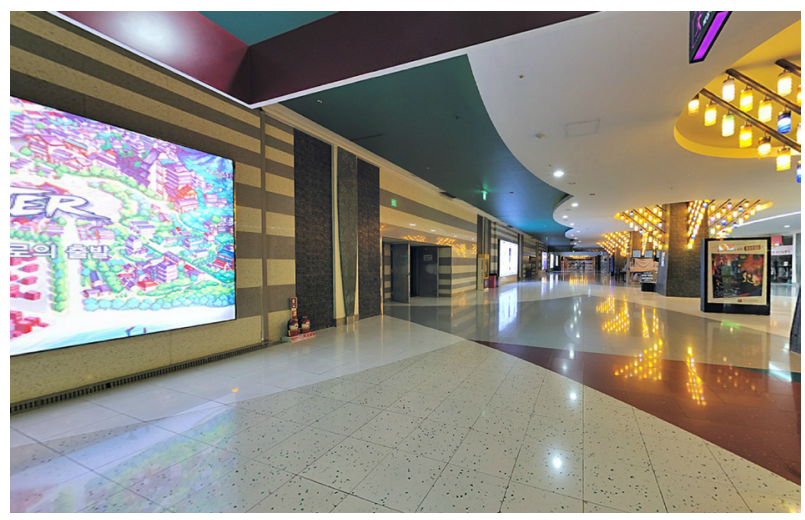

Figure 2. The exit door of COEX Megabox Movie Theater Complex toward a main corridor

\footnotetext{
${ }_{16}$ Brown, S. (1991) Shopper circulation in a planned shopping center, International Journal of Retail \& Distribution Management, 19(1), 17-24
}

\section{CONCLUSION}

The idea of access convenience in designing a mega mall would be an important factor not only for major tenants but also for small individual general tenants. Also, once an initial tenant mix plan forms, a pedestrian traffic environment will inevitably follow in a certain shape. However, due to its enormous scale, there is a high possibility that visitors will rely on anchor tenants' location to imagine a cognitive map of its whole facility to understand the architectural composition because, in most cases, the size of a mega mall would be beyond general sense in size and function. As a consequence, forming a concentrated anchor tenants territory at the very center of a multipurpose facility as we saw in the COEX Mall will be neither helpful in utilizing an oversized architectural composition nor advantageous for overall commercial activity. Finally, this study came to the conclusion that only an average of $12.63 \%$ exposure rate toward a main circulation path is relatively low compared to the average of $38.97 \%$ in selected U.S. malls and, therefore, the future tenant mix plan for COEX Mall should overcome current centralized anchor tenants' arrangement and be re-located to the fringes of its facility to maximize commercial operations. Contrary, in terms of blind spots, only $8.8 \%$ of individual general tenant were not able to be seen from a main circulation path in selected U.S. malls, but these ratio jumped to $47.21 \%$ in the COEX Mall. This fact is indicating that individual general tenants that are located at blind spots that cannot be seen from an arcade/pathway should be reduced to as many as possible and be exposed aggressively towards an arcade/pathway.

Also, besides the analytical facts, based on literature reviews and compositional strategy of selected malls in the U.S, qualitative inference can be made that facilities, which are practically and technically impossible to re-locate due to special technical requirements, may utilize open spaces and pathways near its facility for active commercial activity.

One limitation of this study is that it was not able to propose a specific floor plan that can maximize commercial activity of COEX Mall based on its findings. The significance of this study, however, is that the findings and comparison analysis hopefully will serve as a valuable design reference for 36 new multipurpose facilities scheduled to be built in Korea by 2016 .

\section{REFERENCES}

Abratt, R., Fourie, J.L., Pitt, L.F. (1985) Tenant Mix: The Key to a Successful Shopping Centre, Quarterly Review of Marketing, 15, 19-27

Anita, K., et. al. (2008) Retail Development, 4th Edition, ULI Development handbook series. Washington D.C., ULI-the Urban Land Institute

Bae, B.K (2010) The New Era of U.E.C(Urban Entertainment Center), Fashionbiz, January, 181-187

Berman, B., Evans, J.R. (1995) Retail Management: A Strategic Approach, 6th Edition, Englewood Cliffs, N.J Prentice Hall

Beyard, M.D., et. al. (2001) Developing Retail Entertainment Destinations, 2nd Edition, Washington D.C.: ULI-the Urban Land Institute 
Brown, S. (1991) Shopper circulation in a planned shopping center, International Journal of Retail \& Distribution Management, 19(1), 17-24

Fujita, M. (1989) Urban economic theory: Land Use and City Size, New York, Cambridge University Press

Gruen, V. (1973) Centers for Urban Environment: Survival of the Cities, New York, Van Nostrand Reinhold Company

Ha, S.J., Park, E.K., Ha, M.K., (2009) A Study on the Store Attributes of Urban Entertainment Center, Journal of the Architectural Institute of Korea, 25(9), 151-158

Han, G.Y., Park, A.R., Park, B.K. (2010) The Mechanism of Space Cognition of Large Mixed-use Complex, Journal of Urban Design, 11(2), 199-214

Joe, Y. (2011) America's Most-Visited Shopping Malls, Travel + Leisure, http://www.travelandleisure.com/articles/americasmost-vi sited-shopping-malls

Lee, D.H., et. al. (2004) Shopping Center Development \& Management, Seoul, Diamond Consulting

Lee, H.S., Oh, J.A. (2012) A Study on the Planning Strategy of Tenant Variety and Placement for Urban Entertainment Center, Journal of the Korean Institute of Interior Design, 21(2), 174-185

Lee, K.H. (1997) A Study on Human Behavioral Patterns in Building Fires and Application of Theirs to the Designing of Escape Routes, Journal of the Architectural Institute of Korea, 13(7), 83-93

Sullivan, M. (1988) Leasing Trends: Which Tenant Brings in the Most Rent?, Chain Store Age Executive, May, 92

Wakefield, K.L., Baker, J. (1998) Excitement at the mall: Determinants and Effects on Shopping Response, Journal of Retailing 74(4), 515-539

Yoo, I.K., Choi, S.H. (2011) A Study on the Entertainment Contents Elements of Urban Entertainment Centers for Attraction of consumers, Journal of the Architectural Institute of Korea, 27(1), $39-46$

Yoon, D.K. (2009) Visual Range of a Driver, KoROAD Webzine, 44, 56-57

(Received October 28, 2013/Accepted December 11, 2013) 